the treatment is not perfectly steady (see table). This disadvantage seems merely theoretical, however, and it is unlikely that it might be harmful. Good clinical results were obtained in our series of 23 patients: mortality was low and not directly related to the diabetic decompensation; the percentage fall in glycaemia with time was remarkably similar in most patients whatever the degree of initial hyperglycaemia or acidosis $(50 \pm 3 \%$ in five hours), and the pattern of glycaemic response can therefore be easily predicted for any given patient at the start of the treatment. Interestingly, the slower rates of decrease in glucose concentration were observed in three patients with cardiac failure who could not receive large amounts of fluid. This re-emphasises the fact that early and vigorous fluid replacement remains an essential part of the treatment of diabetic coma whatever the insulin regimen used. Hyperketonaemia took longer to correct than hyperglycaemia and several patients were still ketotic when glycaemia had returned to a level of about $13.9 \mathrm{mmol} / \mathrm{l}$ (fig 2). Similar observations were made by Soler et $a l^{13}$ irrespective of the mode of administration and the amount of insulin given to the patient. Finally, none of our patients showed late hypoglycaemia or hypokalemia.

The dose of $5 \mathrm{IU} /$ hour was effective in all but two cases: in one patient the decrease in plasma glucose was unusually low, and in the other injections of $20 \mathrm{IU} /$ hour were needed to obtain a significant hypoglycaemic action. This resistance to insulin was probably related to the severity of the clinical state; the first patient was in deep coma with severe dehydration, hypovolaemic shock, and hypothermia, and the second one presented bacterial endocarditis with multiple cerebral infarctions, and cardiac and renal failure. In the second patient relative insulin resistance existed before the acute episode since decompensation developed while she was treated with $120 \mathrm{IU} /$ day. Thus some patients may be refractory to these low-dose insulin regimens.

In conclusion, our results indicate that hourly intravenous boluses are a convenient and efficient way of administering insulin in the treatment of diabetic coma. The hormone can easily be injected through the tubing used for the fluid replacement. This mode of administration is much simpler than the constant infusion technique; even small hospitals with reduced medical staff should be able to apply this technique routinely. If, under careful monitoring, resistance to the standard dose of $5 \mathrm{IU} /$ hour occurs the insulin dose can easily be increased to 10-20 IU/hour or more if necessary. A clinical trial on the routine use of $20 \mathrm{IU} /$ hour is in progress.

We thank Dr Cornil for his constant interest; the nurses and medical staff of the intensive care unit for their help in caring for the patients; and Mrs M A Neef for her excellent technical help.

Requests for reprints should be addressed to Dr N Clumeck, Service de Médecine Interne, Hôpital Saint Pierre, 322 rue Haute, B-1000 Bruxelles, Belgium.

\section{References}

${ }^{1}$ Alberti, K G M M, Hockaday, T D R, and Turner, R C, Lancet, 1973, 2, 515.

${ }^{2}$ Kitabchi, A E, Ayyagari, V, and Guerra, S, Diabetes, 1975, 24, suppl No 2, p 396.

${ }_{3}^{3}$ Moseley, J, British Medical fournal, 1975, 1, 59.

${ }^{4}$ Kidson, W, et al, British Medical fournal, 1974, $2,691$.

5 Page, M McB, et al, British Medical fournal, 1974, 2, 687.

${ }^{6}$ Piters, K, Goodman, J, and Bessman, A, Diabetes, 1975, 24, suppl No 2, p 396.

'Semple, P F, White, C, and Manderson, W G, British Medical fournal, $1974,2,694$.

8 Sönksen, P H, et al, Lancet, 1966, 2, 155.

9 Turner, R C, et al, fournal of Clinical Endocrinology and Metabolism, 1971, 33, 279.

${ }^{10}$ Clumeck, N, et al, Lancet, 1975, 2, 416.

${ }^{11}$ Herbert, V, et al, fournal of Clinical Endocrinology and Metabolism, 1965, $25,1375$.

12 Williamson, D H, Mellanby, J, and Krebs, H A, Biochemical fournal, $1962,82,90$.

${ }^{13}$ Soler, N G, et al, Lancet, 1975, 2, 1221.

${ }^{14}$ Alberti, K G M M, and Hockaday, T D R, Lancet, 1975, 2, 547.

${ }^{15}$ Kraegen, E W, et al, British Medical fournal, 1975, 3, 464.

\title{
Acute responsiveness to calcitonin in chronic renal failure
}

\author{
M COCHRAN, CARMEL J HILLYARD, G J DEW，T J MARTIN
}

British Medical fournal, 1976, 2, 396-398

of the initial plasma phosphate level but was unrelated to the initial plasma calcium level. Plasma hydroxyproline levels were not significantly different in the two groups and were unaffected by calcitonin. In 11 patients fasting plasma calcitonin levels were undetectable with an assay sensitive to $0.1 \mathrm{ug} / \mathrm{l}$. Calcitonin seems to have an acute effect in chronic renal failure which may not operate by arresting bone resorption but is dependent on the plasma phosphate concentration. phosphate levels, but in nine patients both concentrations were substantially reduced after calcitonin. This hypocalcaemic and hypophosphataemic effect was a function

Renal Unit, Northern General Hospital, Sheffield S10 2RX

M COCHRAN, MD, MRCP, senior medical registrar

Endocrine Unit, Royal Postgraduate Medical School, Hammersmith Hospital, London W12 OHS

CARMEL J HILLYARD, BSC, research assistant

Tissue Physiology, Strangeways Research Laboratory, Cambridge G J DEW, AIST, technical officer

Department of Chemical Pathology, University of Sheffield Medical School, Sheffield S10 2RX

T J MARTIN, MD, FRACP, professor of chemical pathology

\section{Introduction}

Calcitonin was discovered as a hypocalcaemic hormone, but there is no evidence to suggest that it has a role in regulating plasma calcium levels in normal adults. It acts by inhibiting bone resorption,,$^{12}$ and it is therefore not surprising that its hypocalcaemic effect is best seen when bone resorption is increased -for example, in stages of rapid growth or in conditions such as Paget's disease or thyrotoxicosis. ${ }^{3-5}$

The effectiveness of calcitonin in treating Paget's disease is based on its ability to inhibit osteoclastic bone resorption. ${ }^{3-6}$ Since parathyroid hormone-stimulated increases in bone resorption in patients with chronic renal failure may lead to painful bone disease and fractures, the present study was begun on the 
premise that calcitonin might be useful in controlling excessive bone resorption in chronic renal failure. There are reports, however, suggesting that high circulating levels of endogenous hormone are already present in these patients, ${ }^{7}{ }^{8}$ which would imply that exogenous calcitonin would have little or no effect. To clarify this, the acute effects of calcitonin were examined in a group of patients with chronic renal failure; the investigation also pointed to certain features of the action of calcitonin that may be relevant to its use in this condition.

\section{Patients and methods}

Seventeen patients (10 men, seven women) gave their informed consent to the study. All were well established on home haemodialysis. Their ages ranged from 20 to 47 years and their weights from 50 to $75 \mathrm{~kg}$. All tests were carried out in the fasting state on the day after dialysis, and the patients avoided gelatin-containing foods for the previous 24 hours.

Responsiveness to calcitonin injection was tested in all patients. On the day of the test two blood samples were taken about one hour apart, and then $160 \mathrm{MRC}$ units of porcine calcitonin (Calcitare, Armour) was given in $1 \mathrm{ml}$ gelatin by intramuscular injection. Blood was taken every two hours for six hours thereafter and a final sample at 10 hours. The patients were allowed a light meal at about eight hours. Heparinised blood samples were separated within 10 minutes and plasma taken for measuring calcium, phosphorus, alkaline phosphatase, and hydroxyproline concentrations. The means of the pre-injection results were taken as the basal values for calcium and phosphorus.

On a separate occasion blood was taken from 11 of the patients for estimating plasma calcitonin levels before and 10 minutes after the intravenous injection of $10 \mathrm{ml} 10 \%$ calcium gluconate, since calcium infusion has been shown to increase calcitonin levels in normal man. ${ }^{9}$ The blood was taken into chilled heparin tubes and the plasma separated and frozen within 15 minutes.

Plasma calcium, phosphorus, and alkaline phosphatase levels were estimated by standard automated (Vickers) techniques. Plasma free hydroxyproline was measured as the amount of pyrrol formed after oxidation with chloramine $T$ after alcohol precipitation of protein.10 In four patients whose hydroxyproline levels were normal, the plasma concentration was measured before and four hours after the administration of gelatin alone. Plasma calcitonin was measured by radioimmunoassay. ${ }^{11}$

\section{Results}

In nine of the 17 patients calcitonin injection was followed by a fall in plasma calcium of at least $0.25 \mathrm{mmol} / \mathrm{l}(1 \mathrm{mg} / 100 \mathrm{ml})$ during the next six hours, whereas the remaining eight patients showed no such response (fig 1). The initial plasma calcium level showed greater variability (range 2.15 to $2.98 \mathrm{mmol} / 1(8.6$ to $11.9 \mathrm{mg} / 100 \mathrm{ml})$ ) within the former group than within the latter (range 2.23 to $2.65 \mathrm{mmol} / \mathrm{l}$ $(8.9$ to $10.6 \mathrm{mg} / 100 \mathrm{ml}$ )) (fig 1). The group showing the hypocalcaemic response tended to have higher alkaline phosphatase levels (mean $\pm S E$ of mean, $36 \pm 8.9 \mathrm{KA}$ units) ithan the remaining patients $(21 \pm 2.0 \mathrm{KA}$ units), but these differences were not significant. No change occurred after calcitonin. The results in fig 2 show that the patients whose plasma calcium concentrations were lowered by calcitonin also had a lowering of phosphorus, whereas there was little or no change in phosphorus levels in the other group.

The group whose calcium and phosphorus levels were lowered by calcitonin had a significantly higher $(P<0.05)$ mean initial plasma phosphorus concentration $(1 \cdot 88 \pm 0 \cdot 15 \mathrm{mmol} / \mathrm{l}(5 \cdot 8 \pm 0.5 \mathrm{mg} / 100 \mathrm{ml}))$ than the non-responders $(1 \cdot 24 \pm 0 \cdot 10 \mathrm{mmol} / 1(3.8 \pm 0.3 \mathrm{mg} / 100 \mathrm{ml}))$. When the initial plasma phosphorus level was related to the hypocalcaemic response (measured in arbitrary units as the area enclosed by the curve as the plasma calcium decreased from its basal value) a highly significant association was found (fig 3; $P<0.005 ; r=0.66$ ). The hypophosphataemic response, measured similarly, correlated significantly with both the initial plasma phosphorus level $(P<0.05$; $r=0.54)$ and the hypocalcaemic response $(P<0.05 ; r=0.53)$. There was no significant relation between the hypocalcaemic response and either the initial plasma calcium or the plasma alkaline phosphatase levels.

The initial plasma free hydroxyproline level was raised $(<2 \mathrm{mg} / \mathrm{l})$ in six out of eight of the patients showing the hypocalcaemic response and in three non-responders, but these differences are not significant and there was no correlation between hydroxyproline level and hypocalcaemic response. Calcitonin had no significant effect on plasma free hydroxyproline (fig 4). In the patients who received gelatin alone a mean rise in plasma hydroxyproline of $3.4 \mu \mathrm{mol} / 1(0.45 \mu \mathrm{g} / \mathrm{ml})$ (range 1.5-4.6 $\mu \mathrm{mol} / 1(0.20-0.60 \mu \mathrm{g} / \mathrm{ml})$ ) was observed four hours after injection, and allowing for this artefact should not significantly alter the result in those patients whose hydroxyproline level was initially raised. Using radioimmunoassay, which can detect plasma calcitonin to levels of $0.1 \mu \mathrm{g} / \mathrm{l}$, no measurable calcitonin was found in any of the patients' samples, even after the calcaemic stimulus. In two patients in whom the sample was extracted by Spherosil XOA 400 and concentrated tefore assay 12 the fasting calcitonin levels found were $51 \mathrm{ng} / \mathrm{l}$ and less than $8 \mathrm{ng} / \mathrm{l}$. These levels were within the normal range $(<8-79 \mathrm{ng} / \mathrm{l})$.

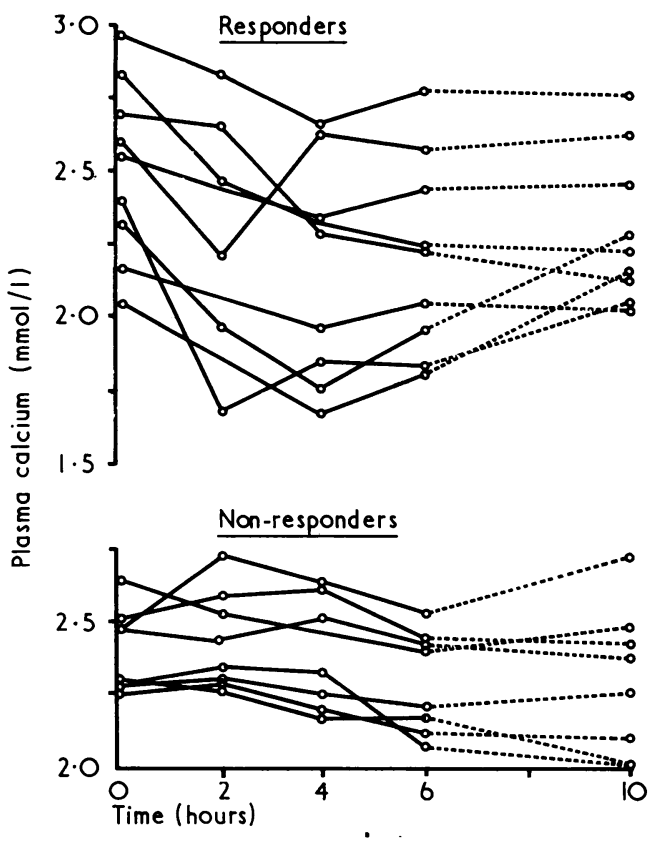

FIG 1-Effect of calcitonin on plasma calcium in chronic renal failure. Patients were not fasting during last four hours.

Conversion: SI to traditional units-Calcium: 1 $\mathrm{mmol} / \mathrm{l} \approx 4 \mathrm{mg} / 100 \mathrm{ml}$.

\section{Discussion}

Large doses of calcitonin have no effect on plasma calcium levels in normal adults. ${ }^{513}$ Our results show that patients with chronic renal failure may respond to calcitonin with a lowering of plasma calcium levels, but this response seems to be related to the prevailing level of plasma inorganic phosphorus. When calcitonin has a hypocalcaemic effect in man it is assumed that this is due to an acute arrest of bone resorption. If this were the case in these patients with chronic renal failure it would imply that high bone turnover states are limited to those patients with hyperphosphataemia and, in view of the close correlation between the hypocalcaemic response and the initial plasma phosphorus level would imply also that bone resorption rate was directly proportional to the plasma phosphate level. Although this is possible it seems unlikely, particularly since there was no relation between the plasma hydroxyproline and plasma phosphate levels, with patients in both the responding and nonresponding groups having raised hydroxyproline levels.

These data suggest that calcitonin primarily facilitates the flow of phosphate out of plasma into some other compartment, and this movement of phosphate may be an important early event in the action of the hormone in these patients with chronic renal failure. While the net hypocalcaemic response is directly related to the initial plasma phosphorus level, it is perhaps surprising that the latter correlates less well with the phosphorus lowering effect. This may be due to a continuing back-diffusion of phosphate from other sources unaffected by the calcitonin. 


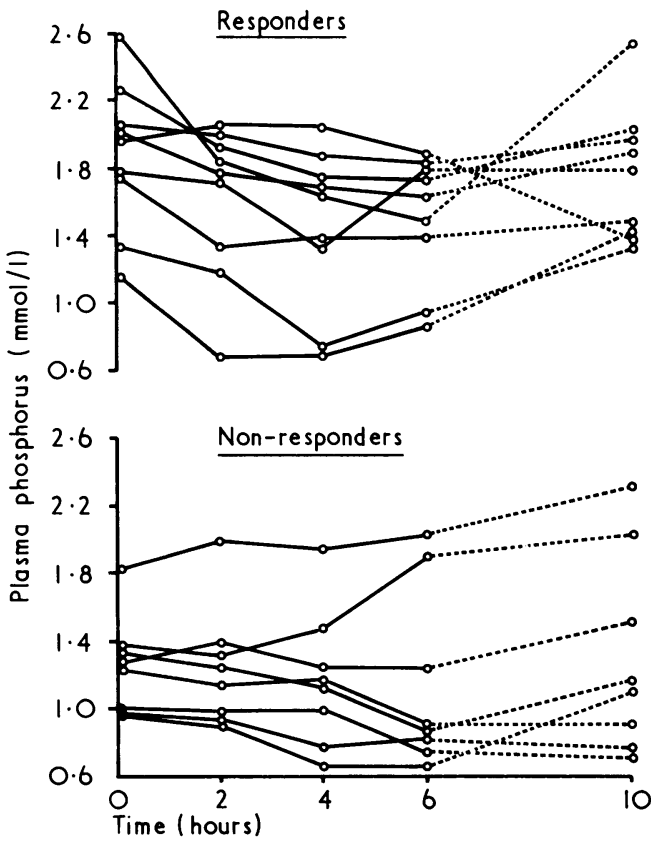

FIG 2-Effect of calcitonin on plasma phosphorus in chronic renal failure.

Conversion: SI to traditional units-Phosphorus: $1 \mathrm{mmol} / 1 \approx 3 \cdot 1 \mathrm{mg} / 100 \mathrm{ml}$.

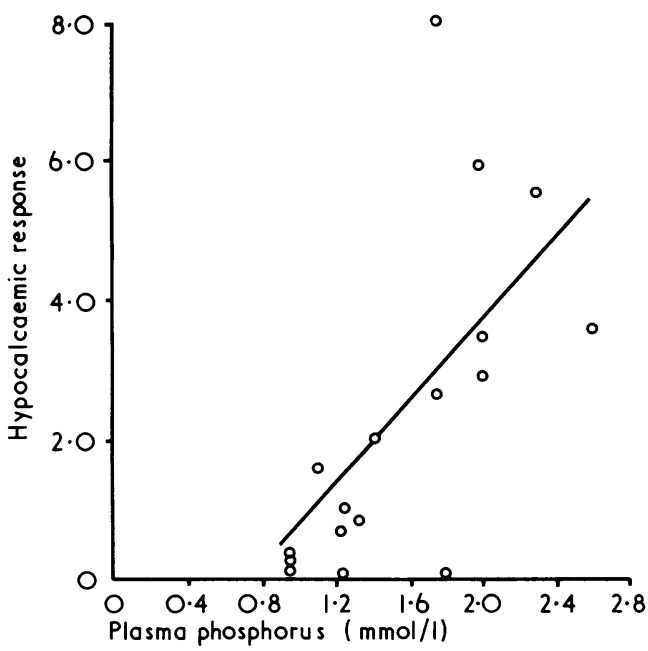

FIG 3-Relation between initial plasma phosphorus levels and hypocalcaemic effect of calcitonin.

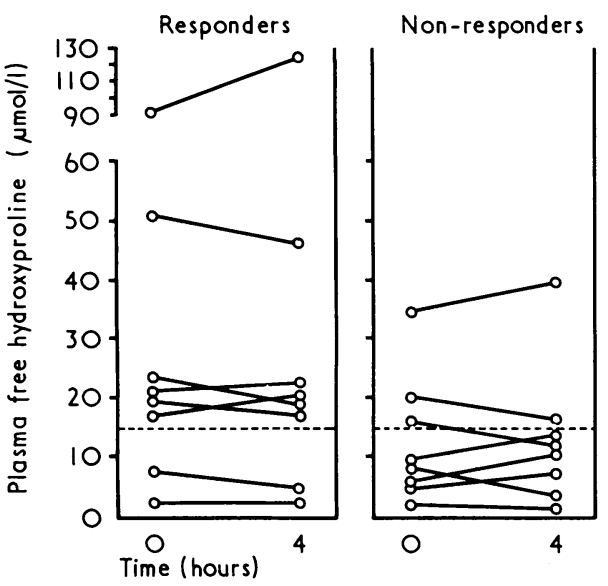

FIG 4-Plasma free hydroxyproline levels before and after calcitonin injection. Upper limit of normal is indicated by broken line.

Conversion: SI to traditional units-Hydroxyproline : $1 \mu \mathrm{mol} / 1 \approx 0.13 \mu \mathrm{g} / \mathrm{ml}$.
The suggestion that calcitonin may have a primary effect on phosphate removal from plasma is not new, having been made by Talmage $e t a l^{14}$ in studies in the rat. Hirsch $e t a l^{15}$ also found that giving phosphate together with calcitonin enhanced the calcium-lowering effect of the hormone in the assay rat, and Gerschberg et al ${ }^{16}$ made a similar observation in man during the treatment of Paget's disease with calcitonin. A relation between the fall in plasma calcium and the initial plasma phosphorus level was noted by Kanis and Strong ${ }^{17}$ in patients with Paget's disease who were given calcitonin, although these patients were generally normophosphataemic, and Hamilton ${ }^{18}$ found in three patients with Paget's disease that clinical resistance to calcitonin could apparently be overcome by giving oral phosphate in addition to the hormone. In a group of patients receiving radiophosphorus therapeutically Paillard et $a l^{19}$ found an enhanced removal of phosphorus from the plasma without alteration in the rate of back-diffusion after salmon calcitonin.

There is a case to be made for testing the therapeutic effectiveness of calcitonin in some patients with chronic renal failure. The present results draw attention to the possibility that extracellular phosphate may be important in modifying certain early events in calcitonin action in these patients. The practical importance of this is obvious when one considers the importance ascribed to plasma phosphate control in chronic renal failure with the use of phosphate-binding gels.

Evidence has been produced ${ }^{20}$ that plasma calcitonin levels are raised in chronic renal failure in direct proportion to the plasma phosphate levels. This contrasts with our own results, in which radioimmunoassay did not indicate raised levels, and, furthermore, the effect of a fixed dose of calcitonin was maximal in those patients with the greatest degree of hyperphosphataemia, suggesting that raised levels of biologically active endogenous hormone are unlikely in this situation. Although levels of calcitonin above $0.1 \mathrm{~kg} / \mathrm{l}$ were not found in our patients, this does not entirely preclude the possibility that their levels were nevertheless above those of the normal population. In view of the widely discrepant normal ranges currently reported ${ }^{7-912}$ the question cannot be answered at present. Whatever the radioimmunoassay results indicate, however, the biological data point to a sensitivity to calcitonin in chronic renal failure which may be mediated by an important effect of the hormone on phosphate metabolism.

We thank the technicians of the department of chemical pathology, Northern General Hospital, Sheffield, for the automated plasma analyses.

\section{References}

1 Friedman, J, and Raisz, L G, Science, 1965, 150, 1465.

2 Martin, T J, Robinson, C J, and MacIntyre, I, Lancet, 1966, 1, 900.

3 Bijvoet, O L M, Sluys Veer, J van der, and Jansen, A P, Lancet, 1968, 1 876.

* Cochran, M, et al, in Calcitonin, ed S Taylor and G Foster, p 523. London, Heinemann, 1970.

${ }^{5}$ Martin, T J, and Melick, R A, Australasian Annals of Medicine, 1969, 18, 258.

6 Woodhouse, N J, et al, Clinical Science, 1970, 39, 9.

7 Silva, O L, Snider, R H, and Becker, K L, Clinical Chemistry, 1974, 20,

${ }^{8}$ Heynen, G, and Franchimont, P, European fournal of Clinical Investigation, 1974, 4, 213.

9 Parthermore, J G, and Deftos, L J, Fournal of Clinical Investigation, 1975, 56, 835.

10 LeRoy, E C, et al, fournal of Biological Chemistry, 1964, 239, 3350.

11 Coombes, R C, et al, Lancet, 1974, 1, 1080

12 Hillyard, C J, et al, in preparation.

13 Singer, F R, et al, fournal of Clinical Investigation, 1972, 51, 2331.

14 Talmage, R V, Anderson, J B, and Cooper, C W, Endocrinology, 1972, 90, 1185.

15 Hirsch, P F, and Munson, P L, Physiological Reviews, 1969, 49, 548.

${ }^{16}$ Gerschberg, $\mathrm{H}$, et al, fournal of Clinical Endocrinology and Metabolism, 1973, 36, 691.

17 Kanis, J A, and Strong, J A, Lancet, 1974, 1, 987.

18 Hamilton, C, American fournal of Medicine, 1975, 56, 35.

19 Paillard, F, Ardaillou, R, and Vallee, G, Clinical Science, 1974, 46, 655.

${ }^{20}$ Heynen, G, and Franchimont, P, Lancet, 1974, 1, 627. 